METODOLÓGICOS E

NOVOS CENÁRIOS PARA

FUNDAMENTOS, ASPECTOS

\author{
SUSTENTABILIDADE

PARA

t

s.

(3) 


\section{SOBRE OS AUTORES}

Julia Weinschenck | juliaweinschenck@gmail.com

Lattes: http://lattes.cnpq.br/3384378479255512

É graduada em Arquitetura pelo Centro Universitário Ritter dos Reis (UniRitter) (2004). Mestre pelo Programa de Pós-Graduação em Arquitetura da Universidade Federal de Santa Catarina (UFSC) (2012) e especialista em Design Estratégico pela Universidade do Vale do Rio dos Sinos (Unisinos) (2017). Atua como arquiteta no Studio Wein, desenvolvendo especialmente projetos de casas de madeira.

Carlo Franzato | cfranzato@unisinos.br

Lattes: http://lattes.cnpq.br/4881062407464026

É designer e doutor em Design pelo Politecnico di Milano. É decano da Escola da Indústria Criativa da Universidade do Vale do Rio dos Sinos (Unisinos). Nessa instituição, é professor dos cursos de graduação, especialização, mestrado e doutorado em Design e supervisor de pós-doutorado. Na perspectiva do design estratégico, sua pesquisa tem como tema central as redes de projeto que se constituem com a abertura do processo de design para as inúmeras colaborações projetuais estabelecidas entre designers e outros profissionais, empresas e organizações, usuários e cidadãos. É membro do grupo de pesquisa Design estratégico: inovação cultural e social e das redes internacionais Latin Network for the Development of Design Processes e Design for Social Innovation and Sustainability. Integra, ainda, o SeedingLAB, laboratório para a prática de design, voltado à inovação social e à sustentabilidade. 


\section{INTRODUÇÃO}

A ilusão provocada pelo conceito de que comprar é sinônimo de satisfação está perdendo sua força. Nesse contexto, o princípio de viver com o essencial tende a crescer, criando uma nova consciência e, consequentemente, um estilo de vida que afeta diretamente 0 comportamento e as escolhas das pessoas. Entra em ação, então, uma geração muito mais responsável e consciente que busca uma vida mais coerente com seus valores, trazendo à tona novas ideias de bem-estar que serão determinantes no futuro. Trata-se de um processo de mudança na direção de uma economia baseada em serviços e conhecimento. Manzini (2003) sintetiza essas transformações em slogans como: "do produto material para o intangivel", "do consumismo para a experiência" e "da posse para o acesso".

Embora esse cenário pareça ser promissor na construção de um estilo de vida mais sustentável, mudanças de comportamento são bem mais complexas e lentas do que aparentam: não é tão simples prever como e em que ritmo essa transição acontecerá. Nesse sentido, ressalta-se que tornar o mundo mais sustentável e a sociedade mais consciente requer um período de transição, pois mudanças de comportamento exigem um processo de aprendizado que leve ao despertar, genuinamente, de novas formas de consumo (MANZINI, 2008; FRANZATO, 2017).

Nessa transformação, torna-se crucial iniciar um processo de design estratégico que articule valores reais para a sociedade como um todo. 0 designer tem a capacidade de contribuir estrategicamente, antevendo algo que ainda não aconteceu e gerando, assim, resultados que motivem e envolvam um grupo de pessoas. Oferecendo soluções inovadoras, o designer é capaz de reconfigurar comportamentos e visões em direção a uma vida melhor (MANZINI, 2003).

Esse movimento é suportado pelo pensamento complexo próprio do design estratégico, que se desdobra a partir de uma perspectiva ecossistêmica (FRANZATO, 2017). Por meio desse processo de abordagem ante desafios de projeto, o designer pode conceber múltiplas visões, ligando diversos fenômenos acerca de um problema, assim como as possiveis perspectivas para solucioná-lo (REYES, 2016). 
Ademais, diversos comportamentos, como padrões de consumo, são profundamente afetados pela arquitetura, uma vez que os espaços atuam como potenciais provedores de bem-estar, capazes de despertar emoções, conectar pessoas, contar histórias e gerar grandes transformações. A atividade da arquitetura envolve, assim, produtos e serviços capazes de gerar inúmeras experiências, fazendo com que os arquitetos, com o objetivo de compreender o desejo dos usuários, busquem conhecer profundamente seu cliente. Trata-se de um processo totalmente personalizado e original que, por essa razão, requer tempo e investimento.

Além disso, a arquitetura tem a responsabilidade social de promover estilos de vida mais sustentáveis e melhorar o cotidiano de uma sociedade, no que concerne ao respeito do meio ambiente e da paisagem, levando em conta o fato de que, com o crescimento da população e a consequente demanda por mais espaços, novas edificações vão se apossando das paisagens naturais e alterando todo um entorno existente. Assim, torna-se especialmente importante incentivar a racionalização dos materiais construtivos, a análise do ciclo de vida e a minimização, tanto quanto possível, do impacto da construção. A esse respeito, pesquisas indicam que a produção da arquitetura tende a se afastar de uma expressão monumental na busca de uma criação mais minimalista e moderada. Tendo isso em vista, o arquiteto Matt Anderson (PSFK, 2015), diretor da Olson Kundig Architects, considera que o design simples e elementar se torna uma resposta pacífica e natural ao caos da vida cotidiana.

Diante disso, o objeto de estudo desta pesquisa é o design estratégico de uma proposta de sistema produto-serviço na área da arquitetura e construção, mais especificamente na produção de casas pré-fabricadas. 0 objetivo consiste em oferecer uma experiência completa e satisfatória, indo além da simples entrega do produto final e considerando todos os momentos envolvidos na compra de uma casa: o pré, o durante e o pós-venda.

A pesquisa torna-se relevante ao apresentar uma nova forma de pensar a atividade da arquitetura, introduzindo uma cultura capaz de desencadear mudanças em diversos setores da vida. Nesse sentido, diante da questão que se enfrenta no desenvolvimento de uma casa pré-fabricada, a contribuição deste trabalho está na construção de diretrizes que sustentem de forma coerente o design estratégico de um sistema produto-serviço de uma casa pré-fabricada. 


\section{PROCESSO DE DESIGN ESTRATÉGICO}

O design estratégico é um método voltado à elaboração de estratégias organizacionais e à inovação, que permite a abordagem de problemas de natureza sistêmica, sendo frequentemente relacionado aos conceitos de metaprojeto e de sistema produto-serviço (SCALETSKY, 2016). 0 metaprojeto destina-se a fornecer uma crítica sobre a prática projetual e seus objetivos, propiciando sua conexão com o método: é, portanto, visto como o projeto do projeto (DE MORAES, 2011).

Trata-se, assim, de um processo orgânico, que ocorre de maneira fluida, permitindo que o problema de projeto seja revisto a cada momento. Franzato e Celaschi (2012) reconhecem a abordagem metaprojetual como uma maneira de fazer avançar uma reflexão sobre o projeto, fundamentando e justificando o contexto que originou o cenário para o qual se destina.

Novas abordagens projetuais fundamentam-se em pesquisas que proporcionem conteúdos indispensáveis para a concepção de produtos e serviços inovadores (FRANZATO; CELASCHI, 2012). Nesse sentido, o primeiro passo consiste na realização de uma pesquisa focada no contexto de partida do projeto - pesquisa contextual -, envolvendo dados disponíveis, análise de tendências, estudos de caso e observação em campo. Somado a isso, recomenda-se realizar uma pesquisa não contextual, conhecida como bluesky, que tem como objetivo fertilizar a criatividade do projeto, isto é, ampliar a maneira de ver o problema de um modo mais intuitivo.

Por meio da articulação entre a intuição e o método, busca-se sintetizar valores determinantes para o projeto. Segundo Franzato e Celaschi (2012), o desafio do designer está justamente em interpretar e utilizar o resultado das pesquisas nas fases da concepção do projeto.

Para que a síntese dos resultados da pesquisa gere instrumentos de projeto, é necessário efetuar a construção de cenários. Trata-se de um instrumento que permite uma passagem fluida, sem solução de continuidade, entre a fase de análise e a fase de síntese (FRANZATO; CELASCHI, 2012). Cenários expressam formas narrativas, isto é, contam histórias, descrevendo o estado das coisas e suas consequências prováveis, diante de certo comportamento adotado pela sociedade. Na esfera do design estratégico, trabalha-se com cenários desejáveis a 
fim de promover o processo projetual. Nesse sentido, são considerados cenários orientados pelo design (MANZINI; JÉGOU, 2006). Segundo Manzini e Jégou (2006), apresentar cenários motivados e alternativos, para ofertas em diferentes contextos, permite que os atores envolvidos no processo de tomada de decisões iniciem uma discussão para comparar visões, chegando a um objetivo comum.

Existem três componentes que constituem a arquitetura de um cenário: a visão, que é o componente mais específico de um cenário, representado por uma imagem hipotética do futuro; a motivação, que legitima a existência do cenário, isto é, lhe dá sentido; e a proposta, representada por um sistema de produtos e serviços necessários para implementar a visão (MANZINI; JÉGOU, 2006, HARTMANN et al. 2012). Manzini e Jégou (2006) esclarecem, ainda, que um cenário é centrado em uma visão, mas consiste em algo diferente de uma visão, elaborada a partir de dados de um cenário. Uma visão pode ser tratada como um tipo de cenário, porém, não precisa ser plausível nem explicitar uma justificativa oferecendo argumentos claros para a discussão. De acordo com os autores, uma visão é constituída de imagens que podem afetar e influenciar o processo, não sendo discutível como ocorre com os cenários, motivo pelo qual se torna um meio de facilitar a percepção entre os atores envolvidos.

A partir das visões propostas, são, então, criados conceitos capazes de atuarem como ponto de partida para um projeto de um sistema produtoserviço, oferecendo condições para comunicar os principais valores e benefícios do produto oferecido (FRANZATO, 2016). Todos os dados adquiridos nesse processo são manipuláveis e podem possuir diversas interpretações, dependendo da perspectiva do designer responsável.

\section{SUSTENTABILIDADE NA ARQUITETURA E A TENDÊNCIA DE CASAS PRÉ-FABRICADAS}

Conforme Manzini (2008) e Franzato (2017), existe uma estreita relação entre design estratégico e sustentabilidade, de modo que, em uma perspectiva ecossistêmica, a elaboração de estratégias organizacionais deveria ser primeiramente orientada a garantir uma existência saudável e douradora a todas as organizações. 
Por definição, o desenvolvimento sustentável é aquele que atende às necessidades presentes da sociedade sem comprometer as necessidades das gerações futuras (UNCED, 1992). Esse conceito não foca somente questões ambientais, pois as ações para um desenvolvimento mais sustentável devem ser amplas, abrangendo, além do meio ambiente (sustentabilidade ambiental), a sociedade (sustentabilidade social) e a economia (sustentabilidade econômica). Precisamente no que concerne à esfera ambiental, Manzini e Jégou (2006) apontam que a transição para uma vida mais sustentável exige um processo de aprendizagem que leve o usuário a evoluir em direção a uma nova consciência, a novas ideias de bem-estar e, principalmente, a novos hábitos de consumo.

Entretanto, diversos fatores impactam negativamente a sustentabilidade, como o crescimento da população, o aumento do consumo e a forte industrialização. No âmbito do Design, com a crescente inovação da tecnologia, surgem produtos cada vez mais desejáveis e rapidamente substituíveis e descartáveis, gerando volumes enormes de resíduos. Assim, torna-se essencial praticar uma economia circular, em que se analisa todo o ciclo de vida do produto, colocando todos os aspectos relacionados à sustentabilidade em análise (MARQUES, 2012).

Nesse sentido, Manzini (2003) explica que um produto deve ser projetado respeitando todas as fases de sua vida. Nessa abordagem, considera-se desde a extração dos recursos necessários para a produção até o último tratamento e destino após o uso do produto.

A partir dessa análise, é possível determinar qual material é o mais viável ao longo do processo e como sua produção afeta o ambiente. 0 papel do design, dessa forma, está em ligar o tecnicamente possível com o ecologicamente necessário, fazendo nascerem novas propostas culturalmente apreciáveis (MANZINI, 2003).

Tais preocupações estão presentes também no projeto arquitetônico, fase em que há grande desperdício de materiais empregados na construção, desperdício esse diretamente relacionado à falta de planejamento. A racionalização da construção pode ser obtida por meio do uso de componentes pré-fabricados, aliado a um sistema construtivo que integre projeto, fabricação, montagem, responsabilidade técnica e acompanhamento. 
Nesse sentido, o mercado da arquitetura tende a demandar, cada vez mais, sistemas racionais, obtendo melhor aproveitamento dos materiais, em uma execução ágil e precisa (BARTH, VEFAGO, 2007). Dos sistemas construtivos racionais, destacam-se os leves, sendo estes os que geram menos impacto ao meio ambiente.

Levando em conta a busca por uma arquitetura mais sustentável, o método construtivo conhecido como wood-frame pode ser considerado um dos mais ecológicos entre os sistemas leves, uma vez que utiliza em sua estrutura madeira oriunda de florestas plantadas. Tendo em vista que a tendência ao consumo de construções mais sustentáveis propicia a ampliação do uso da madeira, a madeira reflorestada surge como uma opção diferenciada em função do reduzido impacto ambiental que provoca (SOUZA, 2010), até mesmo porque a maioria dos materiais construtivos originários advém de fontes não renováveis.

Mesmo secular em diversos países da Europa e da América do Norte, o sistema de casas de madeira pré-fabricadas ainda está longe de ser amplamente adotado no Brasil. A baixa demanda por sistemas industriais está, em parte, associada aos primeiros sistemas pré-fabricados, que tinham como prioridade de projeto a funcionalidade técnica, cujo resultado, na grande maioria das vezes, era uma arquitetura pobre e repetitiva.

Com os novos paradigmas ambientais, desencadearam-se, entretanto, diversas pesquisas que investem nessa alternativa construtiva, propiciando a ampliação e a abrangência de seu uso. Assim, essa tecnologia tem despertado o interesse tanto de usuários quanto de arquitetos e construtores que buscam minimizar os problemas presentes na construção civil convencional e oferecer um produto coerente com o nosso tempo.

A opção por uma casa pré-fabricada evita problemas comuns que ocorrem na construção convencional, tais como: maiores custos derivados de desperdícios, retrabalhos, incertezas, carências nas especificações construtivas ou na implementação tecnológica, despesas não previstas, falta de planejamento, alterações durante a obra e falta de complementação entre projetos (CASTELLS, 2001). Possibilita, ainda, a realização de um planejamento financeiro com mais exatidão, uma vez 
que é possível saber o custo total da obra antes de executá-la, algo que não acontece de forma tão precisa nas obras de alvenaria. Nesse sentido, conforme salienta Bruna (2002), o planejamento da produção é, acima de tudo, um instrumento de otimização no plano qualitativo e econômico do sistema pré-fabricado.

Se no Brasil sistemas pré-fabricados ainda são vistos com desconfiança, no contexto internacional as casas pré-fabricadas alcançam níveis significativos de venda. Essa tecnologia é usada em cerca de 90\% das moradias nos Estados Unidos e tem se popularizado também na Ásia (Isto é, 2011).

Mundialmente, vive-se uma fase de retomada do interesse pelo setor da pré-fabricação na arquitetura, período que iniciou no final da década de 80 do século $X X$, quando os conceitos de construção barata e pouco atraente começaram a mudar. A pré-fabricação de casas está passando, assim, por um momento de inovação e grande interesse, inspirando uma mudança na maneira de pensar a construção de casas e nas formas de morar.

Diante da imprescindibilidade de substituir preconceitos, aliada à necessidade de repensar o sistema da atividade da arquitetura, investir na qualidade do produto e serviço de casas pré-fabricadas de madeira no Brasil mostra-se como um caminho propício. Para isso, características como identidade, qualidade, linguagem e flexibilidade devem ser incorporadas ao projeto.

\section{METODOLOGIA}

Com o objetivo de promover diretrizes para o design estratégico de um sistema produto-serviço para casas pré-fabricadas de madeira, este trabalho enfoca especialmente a elaboracão de cenários que orientam a atividade de design, também conhecidos como design-orienting scenarios (MANZINI; JÉGOU (2006) (HARTMANN;FRANZATO (2012). Um processo de inovação orientada para o design passa por quatro fases de projeto: pesquisa, análise, síntese e realização. Tais fases incluem ver, prever, fazer ver e fazer, habilidades exigidas para um designer (FRANZATO; CELASCHI, 2011). 
Este trabalho se volta a analisar mais profundamente as duas primeiras fases desse processo, pesquisa e análise, uma vez que tem como objetivo definir estratégias conceituais para nortear o projeto. Na primeira fase, realizou-se uma pesquisa contextual (BITTENCOURT; CAMPELO, 2016), destinada a obter recursos para o projeto, buscando conhecimento sobre os caminhos da arquitetura hoje. Em sequência, efetuou-se uma pesquisa não contextual, conhecida como blue-sky, com a finalidade de gerar estímulos criativos que enriqueçam o processo de projeto (SCALETSKY; AMARAL, 2012).

Já na fase de análise, foram construídos cenários desejáveis, mostrando um estado das coisas que poderia existir e buscando, assim, estimular a discussão acerca das possibilidades. Em seguida, cenários foram interpretados e analisados com base nos três componentes que constituem a arquitetura de um cenário: a visão, a motivação e a proposta. A partir dessa análise, procedeu-se a uma reflexão acerca dos resultados com o objetivo de encontrar diretrizes para o desenvolvimento de um sistema produto-serviço para casas pré-fabricadas de madeira.

\section{DESIGN ESTRATÉGICO DO SISTEMA PRODUTO-SERVIÇO}

Conforme descrito na metodologia, nesta seção são apresentadas

as primeiras duas fases de um ciclo de design estratégico, voltadas

à elaboração de cenários e à identificação de diretrizes para o

desenvolvimento de um sistema produto-serviço para casas pré-fabricadas.

\subsection{Pesquisa contextual}

A arquitetura está em fase de forte transformação: muitos arquitetos têm se afastado da produção de uma arquitetura extravagante e monumental, buscando o essencial e moderado (ANDERSON, 2015). Esse movimento vem em resposta ao crescimento da consciência ambiental dos próprios usuários, fazendo com que os arquitetos busquem desenvolver projetos com o mínimo de impacto ambiental e energeticamente mais eficientes, isto é, mais sustentáveis. Em consequência, as características de linguagem desses projetos tendem a ser mais minimalistas e a utilizar materiais naturais. 
Em uma pesquisa realizada em 2015, pelo renomado escritório de pesquisa PSFK, em conjunto com a Architizer, foram relacionadas algumas tendências-chave para construir o amanhã. Tais tendências vão diretamente ao encontro do problema de pesquisa abordado neste estudo, motivo pelo qual são descritas a seguir (PSFK, 2015).

A primeira delas é o crescimento do espírito de comunidade, finalidade para a qual a arquitetura exerce importante função, pois conecta pessoas, podendo ser percebida na demanda crescente por espaços compartilhados e colaborativos. A tendência de lazer intencional propõe uma arquitetura não estática, mas em movimento, visando criar espaços mais vivos, com elementos interativos, que despertem a curiosidade nos usuários e a vontade de envolvimento.

A flexibilidade e adaptabilidade dos espaços também são características mais presentes na arquitetura, tendo em vista que atualmente as atividades das pessoas se misturam: vida pessoal, trabalho e lazer se confundem o tempo todo, sendo, nesse sentido, tratados como estados fluídos. Por essa razão, casas, escritórios e espaços públicos devem suprir múltiplas propostas, apresentando flexibilidade e modularidade como elementos capazes de permitir a acomodação de diversos usos e necessidades.

O desejo por uma conexão interior, voltada ao autoconhecimento, leva ao crescimento da demanda por projetos de espaços que proporcionem paz e silêncio. $O$ conceito de refúgio aparece como uma das tendências, assim como a harmonia com o entorno, que indica a importância crescente do contexto como condicionante principal do projeto e reforça o conceito de que a arquitetura deve ser inseparável do seu entorno. Além da harmonia com a paisagem natural, essa tendência traduz a busca por uma integração cultural, que envolve a escolha de materiais, de fornecedores e de mão de obra locais.

No que diz respeito ao âmbito da sustentabilidade, o exercício da moderação aparece como mais uma das tendências. Embora um discurso arquitetônico relevante, na maioria das vezes, tenha estado vinculado a uma arquitetura monumental, cada vez mais projetos eficientes, em espaços menores e com uma linguagem minimalista e essencial, representarão de forma consistente a expressão arquitetônica no futuro.

Seguindo nessa direção, a segunda vida, obtida por meio do reuso, do reaproveitamento ou da reciclagem, torna-se uma tendência propícia. 
Em oposição a uma cultura descartável, muitos arquitetos estão respondendo de forma consciente e criativa ao optar por materiais recicláveis ou reciclados. Pela mesma razão, prédios abandonados e sem uso estão sendo cada vez mais renovados com novos projetos, despertando um interesse crescente ao combinar o melhor da arquitetura antiga com uma linguagem contemporânea.

Percebe-se, dessa forma, que um projeto mais sustentável se torna uma premissa para os arquitetos. Recursos alternativos de energia especialmente eólica ou solar - estão mais acessiveis, possibilitando que um espaço utilize energia passiva, isto é, produza sua própria energia. A escolha de novos materiais, em combinação com novas técnicas de projeto, também está reduzindo a quantidade de recursos necessários para manter uma casa confortável. Nos Estados Unidos, por exemplo, $30 \%$ a menos de energia é consumida nos edifícios, sendo este o menor nível de consumo energético desde 1975 (PSFK, 2015).

A última tendência apontada na pesquisa consiste na alta tecnologia a serviço da arquitetura. Já existem possibilidades ilimitadas de criar formas com técnicas altamente sofisticadas, como, por exemplo, montagens com drones ou impressões tridimensionais. Essas ferramentas experimentais estão cada vez mais à disposição da criatividade e da inovação.

Analisando essas tendências com vistas ao objeto de estudo em questão, pode-se perceber que muitas vão de encontro ao produto e serviço que se apresenta nesta pesquisa. São elas: a flexibilidade de projeto, podendo este se adaptar às necessidades da vida; a busca por um refúgio, onde se possa ter tempo para conectar-se com a natureza; a necessidade de respeitar o entorno, levando em consideração a cultura e a paisagem natural; o conceito de viver de forma moderada, isto é, viver com menos; a necessidade de utilizar materiais reciclados; e o uso de tecnologias que promovem fontes de energia renováveis, além de ferramentas que estão à disposição, favorecendo o processo criativo e construtivo.

Após a análise de tais tendências, a pesquisa contextual foi complementada com uma breve análise de mercado. Ofertas de casas prontas pré-fabricadas - existem mundialmente, porém, no Brasil, esse mercado tem espaço para crescer. É possivel observar algumas manifestações no formato de containers, uma vez que possuem uma estrutura forte, são descartados após certo tempo de uso no transporte e servem como uma boa opção para 
desenvolver projetos de reutilização. Constituem, assim, uma tendência no mundo, possuindo diversos exemplos de uso de forma bastante criativa. Os pontos negativos, por sua vez, estão associados às medidas, que, por serem padrão para o transporte, são pequenas e limitadas, motivo pelo qual possuem, por exemplo, um pé-direito baixo para os padrões de ergonomia, e também ao conforto térmico, necessitando por serem feitos de aço - material que conduz calor - de um sistema de isolamento para serem utilizados como moradia.

Um exemplo que vem se destacando no Brasil é a Minimood, que oferece casas modulares, feitas com estrutura de aço e entregues prontas e completas no terreno. Tais casas possuem uma arquitetura de alto padrão e já estão sendo exportadas para outros países.

Uma casa pré-fabricada compete no ramo da arquitetura, que desenvolve projetos totalmente exclusivos, indo ao encontro daquilo que o cliente deseja. Como cada projeto é único, pode ser mais bem adaptado ao terreno, levando em conta aspectos como orientação solar e condições naturais. Por outro lado, o processo é mais lento e envolvente e mais vulnerável a possíveis problemas, sendo mais complexo coordenar todas as etapas.

Internacionalmente, o mercado de casas pré-fabricadas já está consolidado e tende a crescer ainda mais. A empresa portuguesa Tree house é um exemplo no que concerne à sustentabilidade e modularidade aplicadas a casas pré-fabricadas de madeira: oferece 15 modelos de módulos que permitem, de forma rápida e criativa, configurar uma casa diretamente pelo site da empresa, sendo a madeira o material que predomina tanto na estrutura quanto no fechamento das construções.

Outro exemplo é a organização americana Method Homes, baseada em Seattle. Os proprietários da empresa, depois de anos atuando na indústria da construção tradicional, acreditaram que deveria haver uma maneira melhor - mais ágil, limpa e precisa - e igualmente atrativa de construir. Combinando seus interesses e sua competência, criaram um negócio que produz casas pré-fabricadas customizáveis.

As casas da Method Homes são construídas em uma unidade própria de produção, por profissionais especializados, e entregues no terreno com uma estrutura pronta que varia entre $80 \%$ e $95 \%$ do total do projeto. Essa empresa busca simplificar ao máximo o processo de construção e 


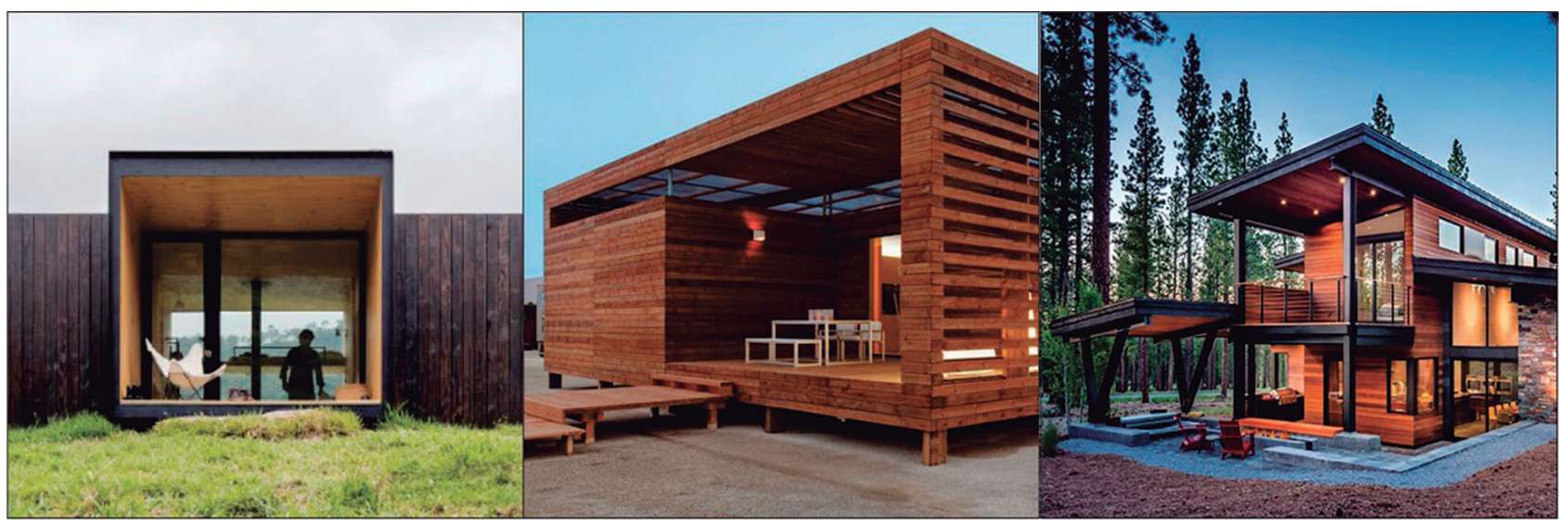

tornar as casas pré-fabricadas acessíveis para o maior número possível de pessoas. A Figura 1, mostra exemplos de projetos elaborados pelas empresas mencionadas.

\subsection{Pesquisa blue-sky}

Por meio da pesquisa blue-sky, foi possivel relacionar os principais valores para o processo de projeto. Foram definidos, então, três contextos que envolvem o projeto: 1) sentimentos relacionados a uma casa; 2) a casa como produto de arquitetura; e 3) o comportamento de vida das pessoas. As Figuras 2 e 3 representam o resultado do exercício.

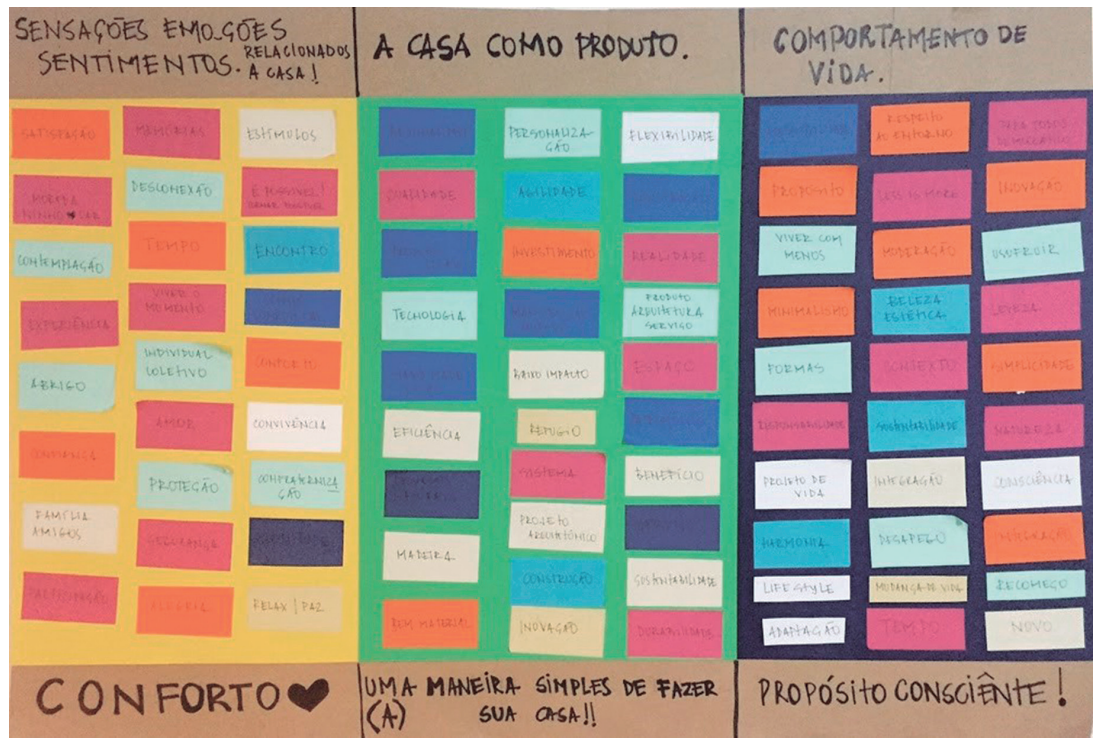

Figura 1: Projetos elaborados em 2017 por MapaArq, Tree House e Method Homes.

Fonte: as imagens foram retiradas, respectivamente, dos sites http:// mapaarq.com/prefab, http://www. treehouse.pt e http://methodhomes.net. Acesso em 10 jul. 2017.

Figura 2. Exercício da pesquisa blue-sky. Fonte: elaborada pelos autores. 
Analisando os conceitos que surgiram, criaram-se três visões importantes. 0 conforto aparece como o significado-síntese de sentimentos relacionados a uma casa, sentimento esse que incorpora a ideia de amor, segurança, família, abrigo, refúgio e confraternização. Uma maneira simples de fazer sua casa, por sua vez, figura como uma visão-síntese dos serviços e produtos que deveriam ser trabalhados para que o ato de construir uma casa fosse simplificado e positivo. Já o propósito consciente sintetiza o comportamento de vida do usuário que se identifica com uma nova maneira de viver a construção de uma casa. Esse usuário, sendo uma pessoa que preza pela qualidade de vida, busca viver com menos e estabelece uma conexão com a natureza, apresentando, ainda, o desejo de mudar de vida, ter mais tempo e ser mais sustentável e consciente.

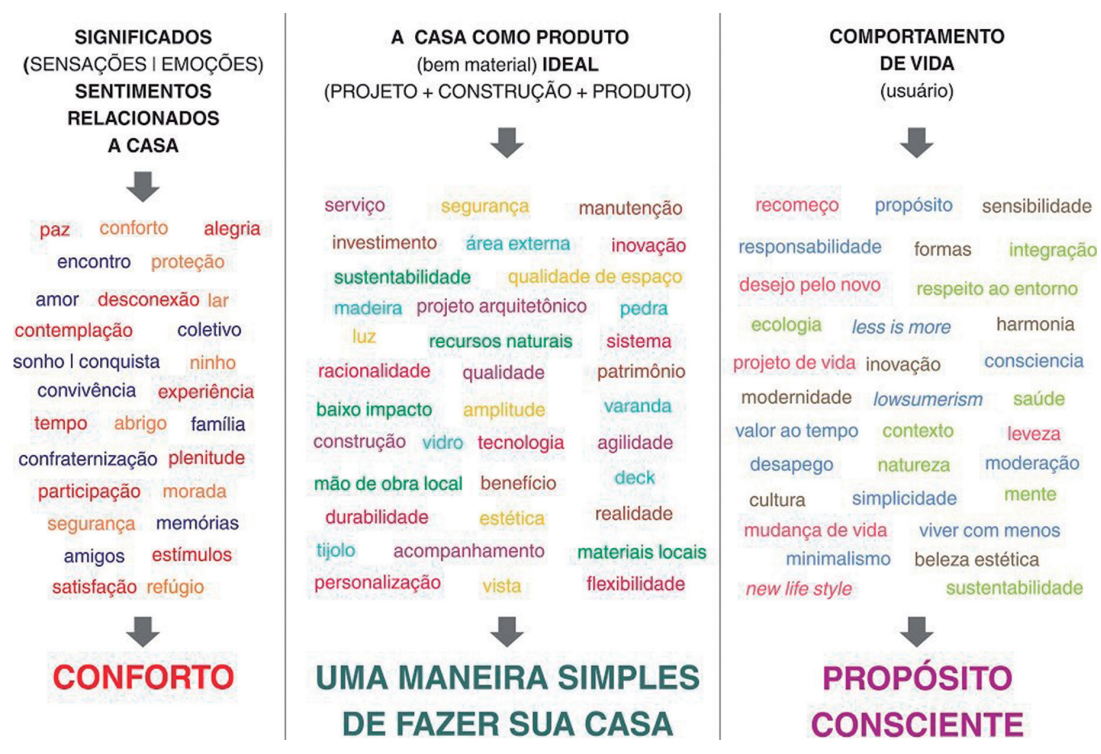

Figura 3: Agrupamento de valores da pesquisa blue-sky. Fonte: elaborada pelos autores.

Tais conceitos de valor - conforto, uma maneira simples de ter sua casa e propósito consciente - foram tratados, então, como o início da construção de um cenário desejável para o projeto, isto é, um cenário que gere base e conhecimento para promover o processo de projeto. A partir disso, buscou-se representar a atmosfera de cada conceito por meio de um painel de imagens-síntese (mood-board), expostas nas Figuras 4, $5 \mathrm{e}$ 6 , que representam o universo dos valores encontrados no exercício. 

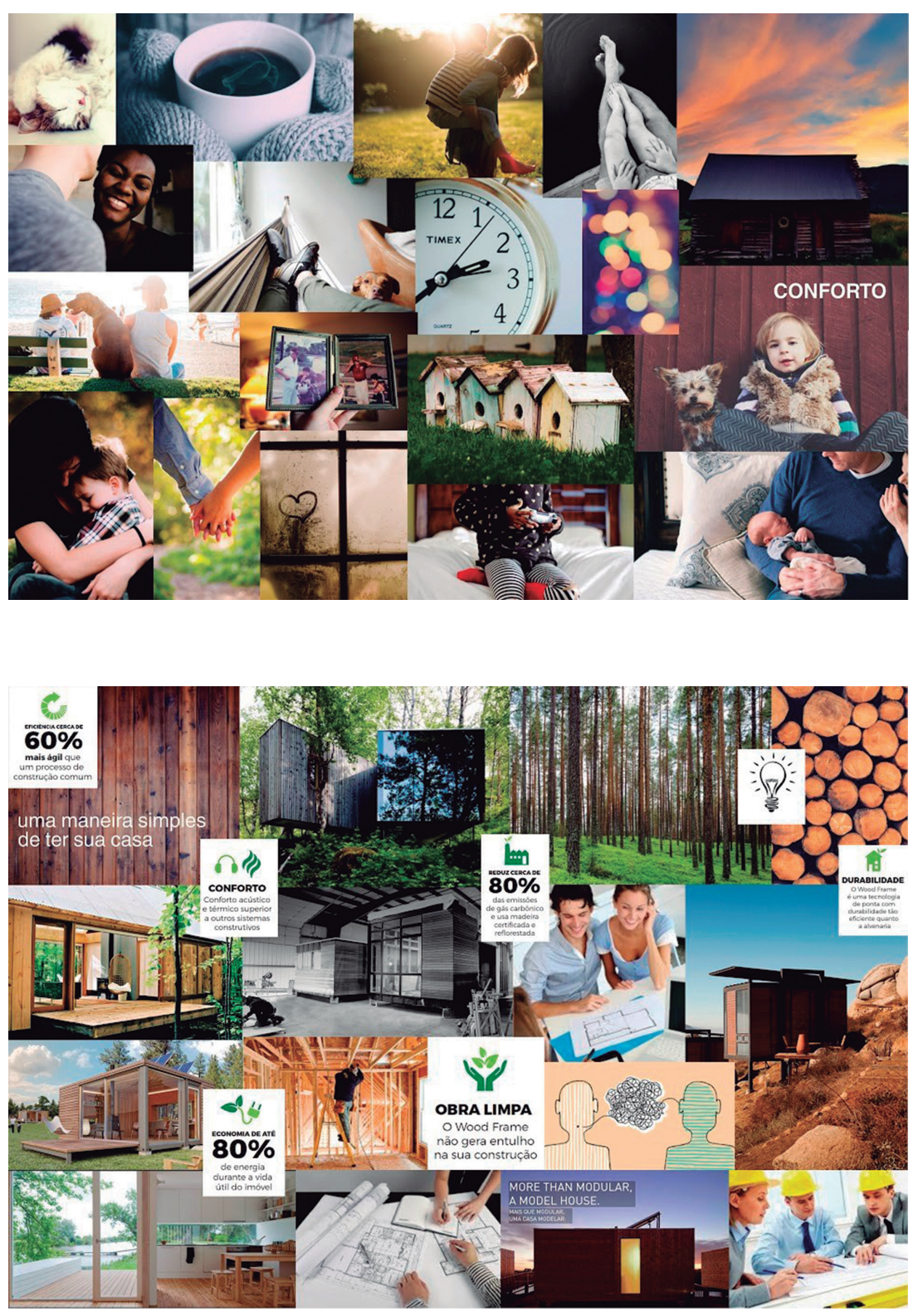

Figura 4: Mood-board conforto. Fonte: elaborada pelos autores.

Figura 5 Mood-board uma maneira fácil de ter sua casa. Fonte: elaborada pelos autores.

\subsection{Cenário}

Os valores encontrados representam a motivação dentro da arquitetura de um cenário. Mostram que existe uma razão para ele existir, isto é, legitimam o cenário, uma vez que estão representados por grupos de imagens que relacionam universos desejados na composição do projeto. 


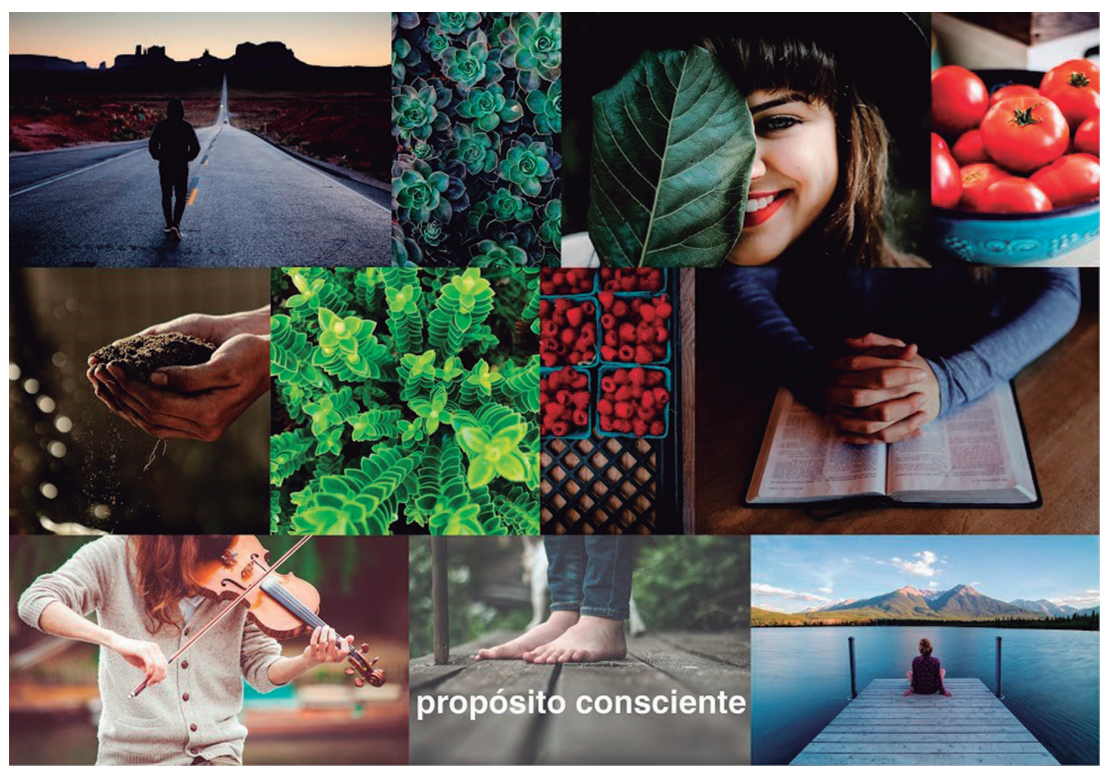

Figura 6: Mood-board propósito consciente. Fonte: elaborada pelos autores.

Após a identificação dos valores, foi utilizada a técnica de construir personas para compreender melhor o público-alvo e os atores envolvidos no contexto estudado. 0 foco, nesse momento, não reside em um ator individual somente, mas, sim, na rede de relacionamentos que articula produtos e serviços, ou seja, nos atores e no ambiente, que são indissociáveis (HARTMAN; FRANZATO, 2012).

A Figura 7 apresenta a persona 01, que representa um profissional que percebeu a oportunidade de inovação no contexto da arquitetura de casas e concebeu a ideia de um novo produto; e a persona 02 , que representa um fornecedor que se interessa por novos projetos, é consciente e busca melhorar o mundo oferecendo um material construtivo sustentável.

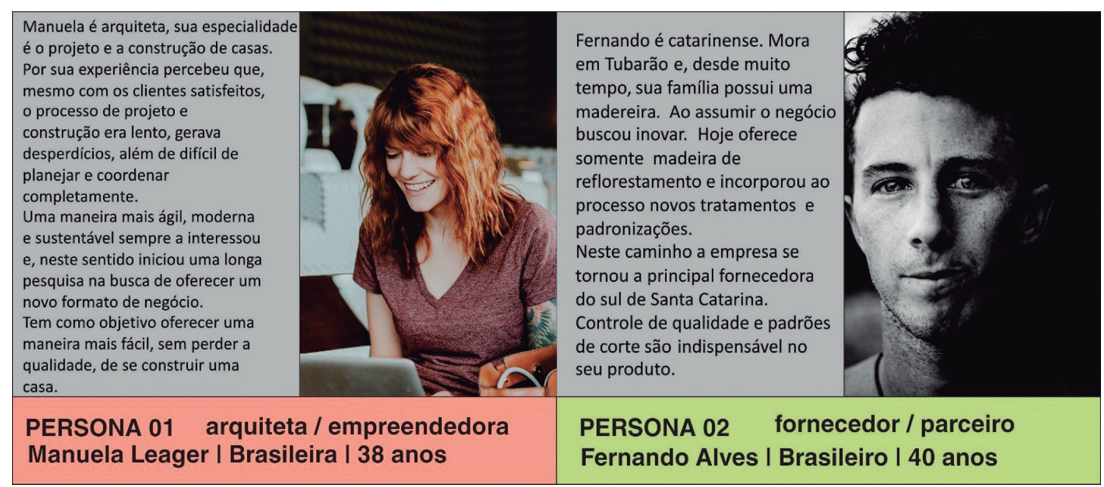


Na sequência (Figura 8), apresentam-se a persona 03, que representa a mão de obra qualificada indispensável ao sistema, fazendo parte da equipe de execução do projeto, e a persona 04, que faz o papel do público-alvo, representando um usuário com potencial de atração pelo produto.

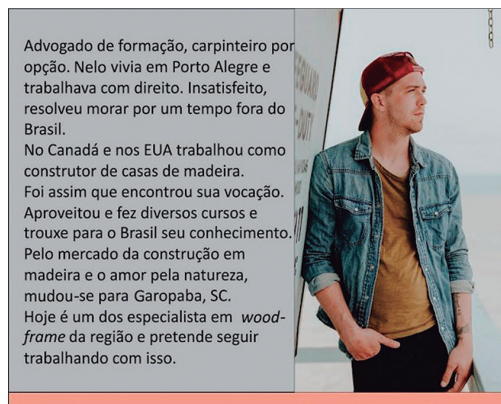

PERSONA 03 mão de obra / parceiro Nelo Guerreiro I Brasileiro I 34 anos

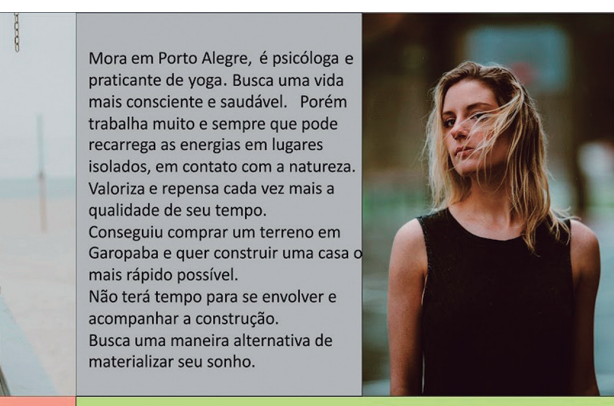

PERSONA 04 potencial usuário / cliente Catarina Fassi I Brasileira I 31 anos
Figura 8: Personas 03 e 04 Fonte: elaborada pelos autores.

Para explorar o componente de um cenário que representa a proposta, isto é, o sistema de produtos e serviços necessários para implementar a visão, foi construído um mapa de ofertas da experiência de compra, relacionando-o com os principais momentos de interação durante a jornada do usuário (Figura 9). Esse mapa buscou explorar e refletir sobre como se articula o sistema produto-serviço.

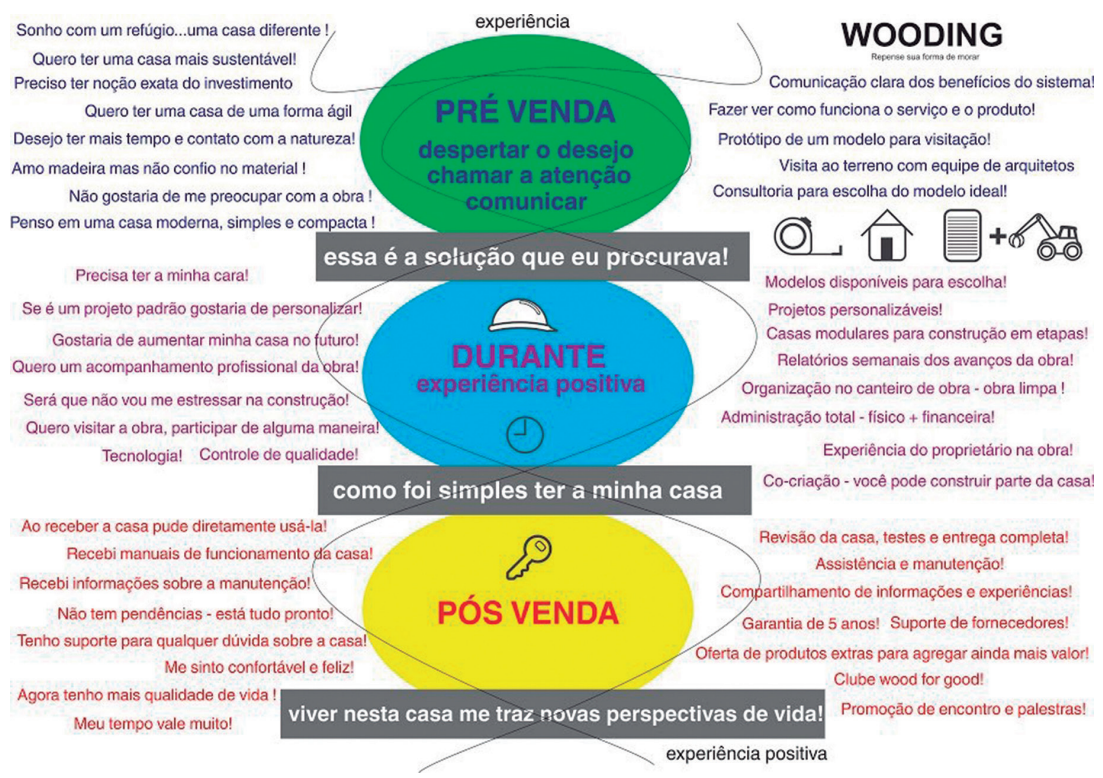

Figura 9: Mapa de ofertas versus jornada do usuário. Fonte: elaborada pelos autores. 


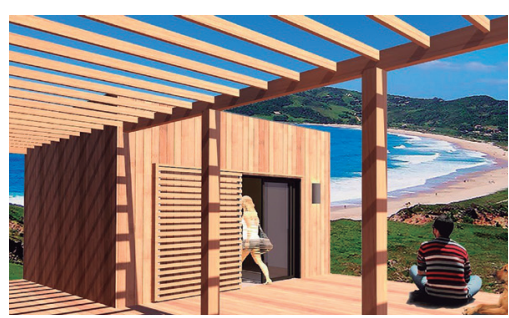

Figura 11: Visão 2. Fonte: elaborada pelos autores
Para Hindrichson e Franzato (2012), cenários permitem a representação da complexidade dos elementos que envolvem um problema e da maneira como uma organização pode enfrentá-los projetualmente. Para os autores, trata-se de uma técnica para configurar os elementos que constituem o contexto de atuação das organizações e, assim, dar condições para que determinadas estratégias sejam cumpridas.

Representando uma situação futura, o cenário auxilia a discutir decisões para maximizar as oportunidades e minimizar o risco, devendo, portanto, retratar os objetivos projetuais e constituir uma forma de organizar o projeto. A representação visual desse cenário permite que se possa ler com clareza e precisão a complexidade do próprio sistema projetual.

Tendo isso em vista, a construção de cenário foi finalizada com o componente da visão, isto é, uma imagem hipotética do produto no futuro, na tentativa de visualizar a solução em uma única imagem (HINDRICHSON; FRANZATO, 2012). Nesse sentido, construíram-se duas imagens (visões), a fim de visualizar contextos alternativos e ambientar, virtualmente, os produtos e serviços propostos no projeto (Figuras 10 e 11).

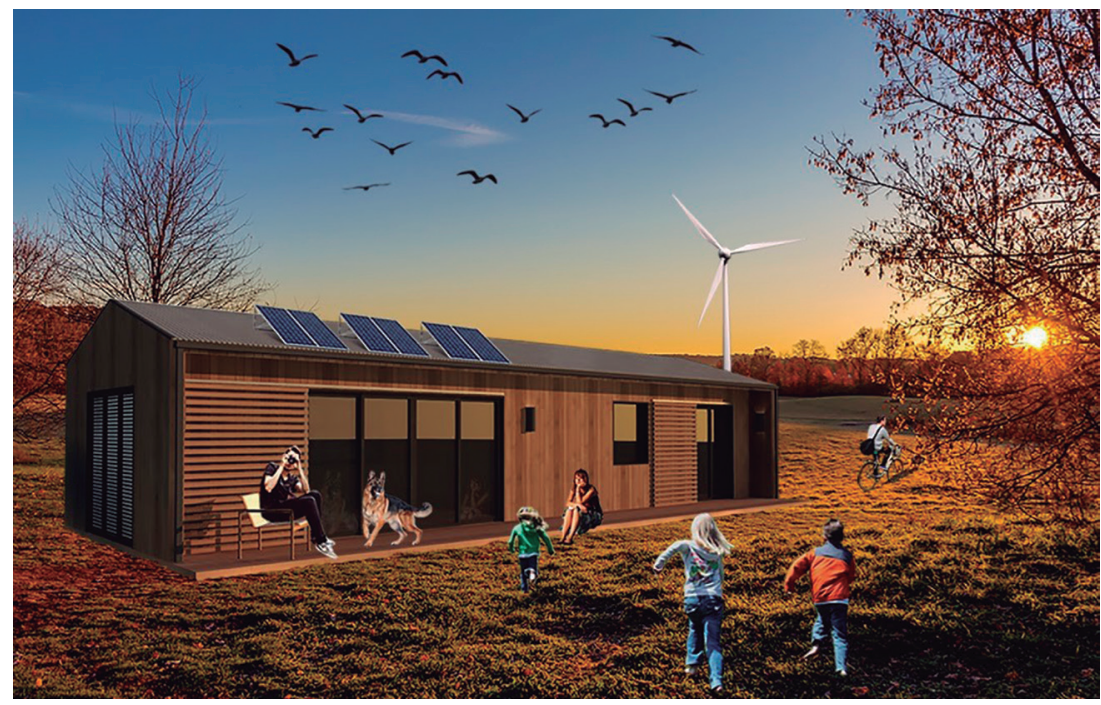

Figura 10: Visão 1. Fonte: elaborada pelos autores. 


\section{DISCUSSÃO}

Visando orientar o design estratégico de um sistema produto-serviço de uma casa pré-fabricada, este trabalho utilizou uma ferramenta metaprojetual para desenvolver cenários orientados para o design. Para isso, realizou-se uma sequência de exercícios e interpretações, originando um conjunto de informações e conceitos coerentes, que servirão como diretrizes no desenvolvimento de um sistema produto-serviço.

A partir dos dados obtidos na pesquisa contextual, percebeu-se que diversas das tendências voltadas à arquitetura convergem com a proposta de projeto em questão, como flexibilidade e adaptabilidade, conceito de refúgio, respeito ao entorno - tanto natural quanto cultural -, projetos moderados e compactos, reutilização de materiais e utilização de energia limpa. Nota-se, assim, que novas ideias de bem-estar, mais coerentes com os propósitos dos usuários, serão premissas para um novo projeto. Nesse sentido, durante a fase da pesquisa blue-sky, sintetizaram-se três possiveis inspirações, materializadas nos moodboards, que traduzem os principais valores relacionados ao projeto. Os mood-boards foram, dessa forma, úteis para figurar diretrizes importantes para promover o processo de projeto, sendo indispensáveis ao fortalecimento de um posicionamento coerente.

Já ao analisar o conceito de uma maneira simples de ter sua casa, cruzando os dados com as necessidades de um usuário consciente, que deseja um processo fácil e acessível e um produto de alta qualidade, desenvolveu-se um mapa de ofertas, indo ao encontro do desejo do usuário durante uma jornada. Nessa etapa, refletiu-se sobre qual sistema de produtos e serviços seria necessário para que a experiência se tornasse satisfatória.

Foram elaboradas, então, duas visões, ou seja, imagens hipotéticas de como seria o futuro se o sistema produto-serviço de casas préfabricadas de madeira realmente acontecesse, com a apresentação por meio de uma imagem, pôde-se ambientar o projeto em possíveis contextos de destino.

Foi possível perceber, a partir disso, que aos cenários corresponde um processo capaz de orientar projetos. Embora os cenários possam ser 
representados de diversas formas, não existindo uma regra, alguns elementos devem estar presentes - a manipulação, interpretação e análise dos resultados acontecem mediante a sensibilidade, percepção, participação e compreensão do projetista, habilidades que um designer estratégico deve incorporar.

Nesse sentido, cabe ressaltar que, em função do tempo disponivel para a execução deste trabalho e da complexidade do processo metaprojetual, esta pesquisa constitui somente um ponto de partida no processo de projeto de um sistema produto-serviço para a produção de casas préfabricadas de madeira, que envolva a experiência completa, de forma inovadora e satisfatória.

\section{CONCLUSÃO}

Inúmeros projetos no mundo ilustram uma crescente propensão para uma reavaliação da arquitetura. 0 cenário caminha, assim, para grandes evoluções tecnológicas, trazendo à tona a importância de buscar a coerência entre o progresso e a essencial prática da arquitetura em torno da compreensão da necessidade humana e do cenário ambiental.

O design estratégico torna-se, diante disso, uma abordagem eficaz para desenvolver um caminho que propicie esse equilíbrio, já que no contexto da arquitetura pouca atenção é dedicada à investigação real da percepção dos usuários sobre o ambiente construído. No caso desta proposta de projeto, que diz respeito a uma solução baseada na oferta de casas prontas, deve-se dedicar esforços para evitar a desumanização do processo de projeto, que é articulado entre o arquiteto e o usuário, uma vez que a necessidade da personalização e exclusividade vai em direção contrária à produção industrial da habitação.

Nesse sentido, torna-se importante a reflexão de Hertzberg (2006) acerca de que, quanto mais influência individual pode ser exercida sobre determinado espaço, mais o usuário se sente emocionalmente envolvido com ele. $O$ autor explica, ainda, que o ideal é fazer com que o ambiente construído possa cumprir mais de um propósito e ter mais de uma interpretação. Assim, cada usuário será capaz de interagir com o ambiente à sua própria maneira, interpretando-o de modo pessoal para torná-lo apropriado ao seu ambiente familiar. 
Dessa forma, desenvolver mecanismos que ofereçam processos de personalização das casas prontas é essencial. O design estratégico entra, nesse contexto, como uma ferramenta eficiente em favor de um entendimento mais profundo de tudo que envolve o âmbito do problema analisado, na tentativa de oferecer uma experiência positiva, que alie a agilidade e simplicidade que o sistema oferece com os significados e sentimentos presentes nos usuários quando se trata de uma casa.

\section{REFERÊNCIAS}

BARTH, Fernando; VEFAGO, Luiz H. Tecnologia de fachadas pré-fabricadas. Florianópolis: Letras Contemporâneas, 2007.

BITTENCOURT, Paulo; CAMPELO, Felipe. Pesquisas contextuais. In: SCALETSKY, Celso Carnos (Org.). Design estratégico em ação. São Leopoldo: Editora Unisinos, 2016, pp. 23-35.

BRUNA, Paulo J. V. Arquitetura, industrialização e desenvolvimento. São Paulo: Perspectiva, 2002.

CASAS de alto padrão e tecnologia de ponta. Revista Referência, n. 77, p. 34-55, mar. 2008.

CASTELLS, Eduardo. Avaliação da aplicabilidade de programas para a qualidade de projeto na elaboração de projetos de edifícios residenciais e comerciais em altura. 2001. 304f. Tese (Doutorado em engenharia de produção) - Universidade Federal de Santa Catarina, Florianópolis, 2001.

DE MORAES, D. Metaprojeto: o design do design. São Paulo: Edgard Blücher, 2010.

FRANZATO, Carlo. Geração de conceitos de projetos In: SCALETSKY, Celso Carnos (Org.). Design estratégico em ação. São Leopoldo: Editora Unisinos, 2016, p. 64-79.

FRANZATO, Carlo. O processo de inovação dirigida pelo design: um modelo teórico. Revista Design, Inovação e Gestão Estratégica, Rio de Janeiro, v. 2, n. 1, p. 50-62, 2011. Disponível em: http://www.cetiqt.senai.br/ead/redige/index.php/redige/article/viewArticle/72, acessado em: 5 de outubro de 2017

FRANZATO, Carlo; Redes de projeto: formas de organização do design contemporâneo em direção à sustentabilidade, In: OLIVEIRA, Alfredo Jefferson; FRANZATO, Carlo; DEL GAUDIO, Chiara (org.). Ecovisões projetuais: pesquisas em design e sustentabilidade no Brasil. São Paulo: Blucher, 2017, p. 99-110. Disponível em: http://openaccess.blucher.com.br/articledetails/09-20544, acessado em: 5 de outubro de 2017.

FRANZATO, Carlo; CELASCHI, Flaviano. Processo de metaprojeto para o desenvolvimento estratégico e a inovação das organizações. In: CONGRESSO BRASILEIRO DE PESQUISA E DESENVOLVIMENTO EM DESIGN, 10, 2012, São Luís. Anais... São Luís: Universidade Federal do Maranhão, 2012.p. 1659-1671. Disponível em: http://www.academia.edu/2510981/ Processo_de_metaprojeto_para_o_desenvolvimento_estrategico_e_a_inovacao_das_ organizacoes, acessado em: 5 de outubro de 2017

HINDRICHSON, Patrícia Hartmann; FRANZATO, Carlo. REYES, Paulo. SCALETSKY, Celso Carnos. A representação dos cenários que orientam o processo de projeto. In: CONGRESSO BRASILEIRO DE PESQUISA E DESENVOLVIMENTO EM DESIGN, 10, 2012, São Luís. Anais... São Luís: Universidade Federal do Maranhão, 2012. Disponível em: https:/www.academia. edu/8955001/A_representa\%C3\%A7\%C3\%A30_dos_cen\%C3\%A1rios_que_orientam_o_ processo_de_projeto, acessado em: 5 de outubro de 2017. 
HINDRICHSON, Patrícia Hartmann; FRANZATO, Carlo. Design de cenários: uma tecnologia para promover o compartilhamento de conhecimentos em redes de projeto. Revista D: Design, Educação, Sociedade e Sustentabilidade, v. 4, n. 4, 2012, pp. 155-168. Disponível em: http://seer.uniritter.edu.br/index.php/revistadesign/article/view/719, acessado em: 5 de outubro de 2017.

HERTZBERG, Herman. Lições de arquitetura. São Paulo: Martins Fontes, 2006.

ISTO É. Casas pré-fabricadas, mas sofisticadas. 2011. Disponivel em: https:/istoe.com. br/124988_CASAS+PRE+FABRICADAS+MAS+SOFISTICADAS/, acessado em: 17 out. 2017.

MANZINI, Ezio. Design para a inovação social e sustentabilidade: Comunidades criativas, organizações colaborativas e novas redes projetuais. Rio de Janeiro: E-papers, 2008.

MANZINI, Ezio. Scenários of sustainnable well-being. Design philosophy papers, n. 1, v. 1, 2003.

MANZINI, Ezio; JÉGOU, François. Design degli scenari. In: BERTOLA, Paola; MANZINI, Ezio, Design Multiverso. Notas de fenomenologia do design. Milano: Edizioni POLI.design, 2006, p. 189-207.

MARQUES, André Canal. Ensino de design e sustentabilidade. In: CONGRESSO BRASILEIRO DE PESQUISA E DESENVOLVIMENTO EM DESIGN, 10, 2012, São Luís. Anais... São Luís: Universidade Federal do Maranhão, 2012.

MOORE, Gary T. Estudos de comportamento Ambiental. São Paulo: Editora Campus, 1984.

UNCED (Conferência das Nações Unidas sobre Meio Ambiente e Desenvolvimento). Declaração do Rio sobre Meio Ambiente e Desenvolvimento. Rio de Janeiro: UNCED, 1992. Disponível em: http://www.onu.org.br/rio20/img/2012/01/rio92.pdf. Acessado em: 5 de outubro de 2015.

PSFK. Building tomorrow. Trends driving the future of design. 2015. Disponivel em: www.psfk. com/report/building-tomorrow, acessado em: 10 jul. 2017.

REYES, Paulo. Projeto por cenários. In: SCALETSKY, Celso Carnos (org.). Design estratégico em ação. São Leopoldo: Editora Unisinos, 2016, pp. 46-64.

SCALETSKY, Celso Carnos (Org.). Design estratégico em ação. São Leopoldo: Editora Unisinos, 2016.

SCALETSKY, Celso Carnos; AMARAL, Laura Guidali, Pesquisa não contextuais. In: SCALETSKY, Celso Carnos (org.). Design estratégico em ação. São Leopoldo: Editora Unisinos, 2016, pp. 35-46.

SOUZA, Anna Freitas Portela. A sustentabilidade no uso da madeira de floresta plantada na construção civil. 2010. 96f. Dissertação (Mestrado em Engenharia Civil) - Universidade Federal de Santa Catarina, Florianópolis, 2010. 